Although the golden eagle will kill either the adult or the young of deer, no evidence was found to indicate that the bird is more than a minor influence when compared to other factors controlling deer populations.

Depending on local conditions, the golden eagle exerts a varying pressure on upland game birds, and at times this pressure may be sufficient to warrant eagle control. The harassing of upland game, thus keeping them from feeding properly in severe weather, may be more serious than the actual killing activities of the eagle. When nesting in the vicinity of waterfowl areas, the golden eagle may feed its young largely on these birds.

Golden eagles at times kill domestic lambs. The extent of this damage varies with local conditions. On occasion, they kill calves or may even contribute to the death of full-grown cattle. All evidence indicates that this is an exceptional activity.

Golden eagles occur in varying numbers on more than sixty-five Federal wild-life refuges where, in general, they serve a beneficial purpose in consuming wounded, sick or dead ducks and forage-consuming jack-rabbits and rodents.

\section{RESEARCH ON FOREST PRODUCTS}

$\mathrm{T}$ HE strength properties of plywood have already been considered in Bulletin No. 29 of the Forest Products Research Laboratory, Princes Risborough, entitled "Comparison of 3-Plywoods of a Standard Thickness, Part 1" (see Nature, 174, 383; 1954). In Bulletin No. 33 on "The Strength Properties of Plywood, Part 2: Effect of the Geometry of Construction"*, the author states that an increasing demand for data on the mechanical properties of plywoods exists; but owing to the wide variety of constructions and thicknesses now available, it is not possible to obtain these data by testing procedures alone. To cover the whole field, some simple methods for estimating strength from limited basic data are required, and this the author sets out to do. This investigation has become necessary because plywoods have become a structural material and can now be produced in forms practically indestructible by delamination. It is stated that increasing quantities are being used, for box and web types of girder, panel floors and walls, ship's planking and concrete shuttering. The trouble is the large variety of thicknesses and different forms of construction, all of which cannot be tested. The coming of plywood in this extensive form of utilization will be very beneficial to the tropical and subtropical forester in charge of forests containing large mixtures of species of trees of which until comparatively recently only $a$ few luxury timbers were marketable. A number of others are now being used, and sylviculturally the management of the forests should become more intensive with the improvement of working plans.

The Bulletin contains the results of an investigation to provide suitable equations for calculating the bending, tension, compression and shear strengths of any plywood construction. All the tests are carried out on African gaboon. From the results, equations

* Forest Products Research. Bulletin No. 33 : The Strength Properties of Plywood. Part $2:$ Effeet of the Geometry of Construction. 28. net. have been formulated which can be used in practice for calculations or constructions of any other species of wood. An appendix to the Bulletin shows how they can be applied.

Bulletin No. 32 of the Forest Products Laboratory entitled "Field Tescis on Wood Preservatives used for Pressure Treatment"* describes experimental work carried out during 1929-53. The lengthening of the life of wood for the various purposes for which it has for so long been used by man has always been a factor for some consideration, especially in tropical countries where perhaps the matter has been more in the forefront of both forester and wood user. So long ago as the 1860's, when railway construction was being carried out on an intensive scale in northern India, the supplies of the valuable Himalayan deodar threatened to give out, and sleepers were.cut from the Pinus longifolia which was abundant in the lower hills. Creosote was brought out from Britain and applied cold without any protective effect. It was more than half a century before the railway authorities tried this timber again for the purpose.

In temperate climates, in Europe at least, some form of preservative for wood structures has for long been under experiment. So far the hightemperature creosotes have proved to be the most effective preservative under test. The method employed is to set out a small 'graveyard' of small blocks of a perishable wood (the agar wood is chiefly used) and these are treated with graded concentrations of the preservative under test, untreated wood blocks being side by side with the treated ones. The treated blocks are kept for a few months with a specific fungus growing on a nutrient agar medium. Periodical examination of the blocks is undertaken, one of the tests being done at Princes Risborough, a second at Thetford and the third at Dolgelly. None is as yet complete.

The results already obtained, however, do give some indication of how effective most of the treatments are likely to be. So far, the high-temperature creosotes have proved to be the best preservative under test; all are highly effective, and after twenty years there is no sign of any difference between them. The lowtemperature creosotes, however, do not appear to be quite so effective. At present there is not much to choose between the various modern water-soluble preservatives under test, although 'Ascu' appears to be the most promising. $\quad$ E. P. STEBbing

* Forest Products Research. Bulletin No. 32: Field Tests on
Wood Preservatives used for Pressure Treatment. By D. N. Smith. Wood Preservatives used for Pressure Treatment. By D. N. S
Pp. iv $+52+1$ plate. (London: H.M.S.O., 1954.) $2 s .6 d$. net.

\section{SPITSBERGEN TERTIARY COAL FOSSILS}

GVEIN MANUM has reported on the pollen-grains $S$ and spores to be observed in coal deposits of Tertiary age in west Spitsbergen (Norsk Polarinstitutt, Med. 79, pp. 1-9; 1954 ; English summary).

The Tertiary formation, of Palæocene-Eocene age, comprises several coal seams of which a preliminary analysis of the contents of pollen and spores has now been made. The numbers of microfossils, as well as their state of preservation, are highly variable. All grains and spores are completely flattened in the coal and do not regain their round shape after maceration. The pollen and spores thus far observed have 